\title{
Preliminary Study of Rapeseed Flour-based Wood Adhesives for Making Wood Flooring*1
}

\author{
In Yang ${ }^{* 2}$, Syehee Ahn*3, In-gyu Choi*4, Gyu-seong Han*2, and Seichang $\mathrm{Oh}^{* 3 \dagger}$
}

\begin{abstract}
Adhesives derived from renewable resources allow wood panel producers to make lower cost alternatives to formaldehyde-based adhesive resins. Among them, adhesive components extracted from industrial by-products or wastes are the most important research fields in the efficient utilization of waste and cost reduction. In our study, the rapeseed flour, which is a by product from the production of biodiesel extracted from rapeseed, was introduced to develop alternative adhesives for the production of wood flooring. The rapeseed flour was hydrolyzed with $1 \%$ sodium hydroxide solution and PF prepolymers were prepared with 3-molar ratios, 1.8, 2.1 and 2.4. The linear fracture mechanics was introduced to evaluate the glue bond quality in wood flooring composed of fancy-veneered and plywood, and the formaldehyde emission and adhesive penetration were also investigated. The formaldehyde emissions of wood flooring met the requirement of the standard of $\mathrm{SE}_{0}$ specified in the KS standard. The rapeseed flour adhesive penetrated sufficiently into the vessel elements and lumens in fancy veneer and plywood and gave strong bond quality to the wood flooring. The fracture mechanics was introduced to evaluate the adhesive joint between fancy veneer and plywood. The critical stress intensity factor $\left(\mathrm{K}_{\mathrm{IC}}\right)$ of boliva overlayed wood flooring was increased with increasing molar ratio and this was the same tendency in oak overlayed wood flooring. From the results, the formulated adhesives were efficiently used to bond fancy veneer onto the plywood to make wood flooring and showed a potential to be used as a component of environmentally friendly adhesive resin systems for production of flooring.
\end{abstract}

Keywords : rapeseed flour, phenol-formaldehyde prepolymer, fancy veneer, formaldehyde emissions, critical stress intensity factor $\left(\mathrm{K}_{\mathrm{IC}}\right)$

\section{INTRODUCTION}

Wood based panels like plywood, particleboard, MDF and wood flooring are manufactured by gluing wood elements under controlled condition. The amount of adhesives used in making wood based panels is estimated about 200,000 tons per year and the production cost of formaldehyde resin adhesives will be increased due to the unstable oil supply and price

*1 Received on September 8, 2011; accepted on September 21, 2011

*2 Department of Wood and Paper Science, Chungbuk National University, Cheongju 361-763, Korea

*3 Department of Forest Resources, Daegu University, Kyongsan 712-714, Korea

*4 Department of Forest Sciences, Seoul National University, Seoul 151-921, Korea

† Corresponding author : Seichang Oh (e-mail: osc@daegu.ac.kr) 
fluctuations.

Urea-formaldehyde adhesive resins used currently for the production of wood based panels emit formaldehyde, and thus the formaldehyde emission causes the critical environmental problems. Consequently, most of advanced countries impose legal controls related to the emission of formaldehyde and classify the class according to the amount of formaldehyde emission. Therefore, it is interested in the development of environmentally friendly new adhesive systems to replace formaldehyde-based resins derived from the renewable resources, such as carbohydrate (Christiansen and Gillespie, 1986), protein (Kuo et al., 2001; Riebel et al., 1997; Steele et al., 1998), tannin (Barbosa et al., 2000) and lignin (Oh et al., 1994; Olivares et al., 1995) for making wood based panels.

The adhesives derived from the renewable resources allow wood panel producers to make lower cost alternatives to formaldehyde-based adhesive resins. Among them, adhesive components extracted from industrial by-products or wastes are the most important research fields in the efficient utilization of waste and cost reduction.

In 2007, rapeseed was imported about 330,000 tons to produce mostly vegetable oils and bio-diesel and it is expected to increase rapidly the rapeseed demand in the production of bio-diesel. The by-product from the production of vegetable oils and bio-diesel, rapeseed flour has been used as feed stuff or dumped as waste. If the efficient utilization method of rapeseed flour is prepared, it leads to get high value added product from industrial waste such as rapeseed flour. The rapeseed flour contains lignin, protein and other components that is able to be used as adhesive constituents. Also this raw material will be possibly used as environmentally friendly new adhesive systems and can replace the considerable amount of the syn- thetic resin adhesives.

The wood flooring is most widely used as the interior materials and limited to its use due to the environmental regulation because the adhesive is used to make the wood flooring and the wood flooring is mainly applied to the indoor condition. Many interests are increased in the environmentally friendly indoor wood products to meet the indoor air quality regulation through reducing the emission of formaldehyde.

Therefore, the objective of this study was to develop the environmentally friendly new adhesive systems using rapeseed flour and to investigate the potential use of rapeseed flour for making wood flooring alternatives to conventional formaldehyde-based wood adhesives.

\section{MATERIALS and METHODS}

\subsection{Materials}

Rapeseed flour obtained from vegetable oil producer was used in the formulations of wood adhesive resins. Technical grade phenol and $37 \%$ formaldehyde (HCHO) purchased from Duksan Pure Co. Ltd. (Ansan, Korea) were prepared for the syntheses of phenol- formaldehyde resins. Sodium hydroxide for the hydrolysis of rapeseed flour was also purchased from Duksan Pure Co. Ltd.

The Oak and Bolivar fancy veneers of dimensions $80 \mathrm{~mm} \times 2 \mathrm{~mm} \times 600 \mathrm{~mm}(\mathrm{~W}, \mathrm{~T}, \mathrm{~L})$ were provided from Dongyang Co. Ltd. (Busan, Korea). The plywood for backing material in wood flooring system was purchased from Shinkwang Co. Ltd. (Incheon, Korea). The plywood dimension was $80 \mathrm{~mm} \times 7.3 \mathrm{~mm} \times 900$ $\mathrm{mm}(\mathrm{W}, \mathrm{T}, \mathrm{L})$ and moisture content was $8 \%$.

\subsection{Resin Preparation}

The rapeseed flour was hydrolyzed with $1 \%$ 


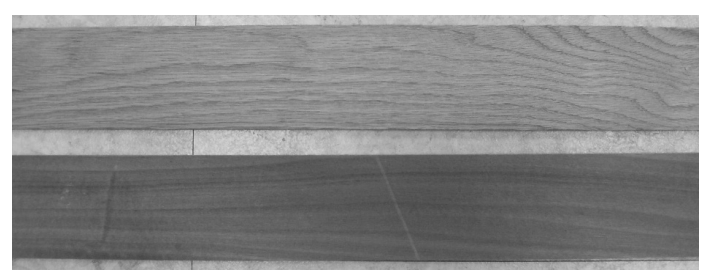

Fig. 1. Materials for making plywood flooring overlayed with fancy veneer (top: oak fancy veneer, bottom: boliva fancy veneer).

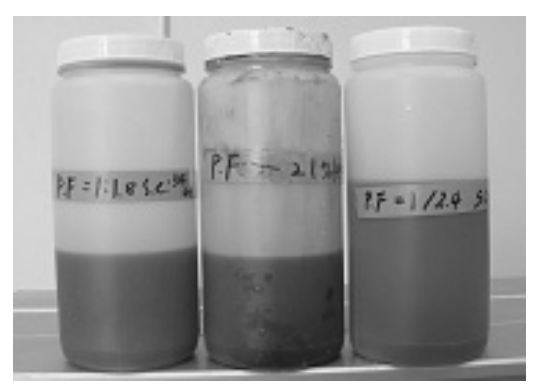

(a) phenol prepolymer

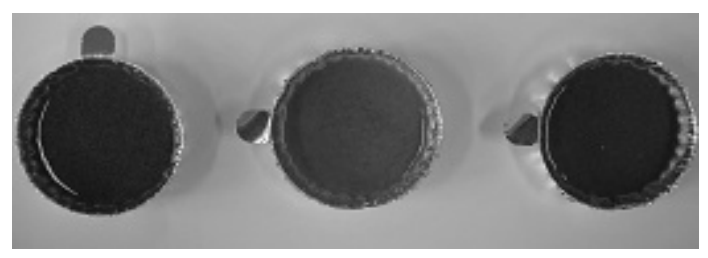

(b) Rapeseed adhesives

Fig. 2. Rapeseed adhesives formulated with phenol prepolymer.

sodium hydroxide solution at $70^{\circ} \mathrm{C}$ for 60 minutes. PF prepolymers were prepared with 3-molar ratios, 1.8, 2.1 and 2.4 and the mixture of phenol, formaldehyde and sodium hydroxide were reacted at $75^{\circ} \mathrm{C}$ for 90 minutes and then refluxed at $95^{\circ} \mathrm{C}$ for 60 minutes. Synthesis reaction of adhesive was carried out at rapeseed flour alkali hydrolyzate to PF prepolymer weight ratios of 70/30 (Fig. 2). After PF was added into rapeseed flour hydrolyzate, then the mixture was stirred at $70^{\circ} \mathrm{C}$ for 10 minutes.

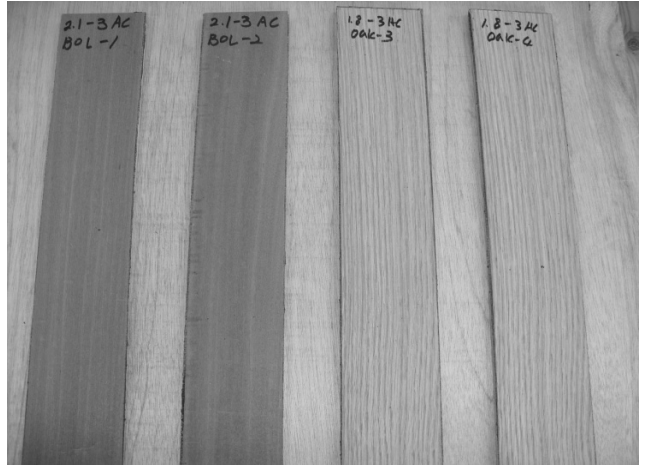

Fig. 3. Wood flooring overlayed with fancy veneer onto plywood using formulated adhesives (red: overlayed with boliva fancy veneer, white yellow: overlayed with oak fancy veneer).

\subsection{Specimen Preparation and Testing}

The prepared resin was applied to the plywood with a brush at a spreading rate of $300 \mathrm{~g} / \mathrm{m}^{2}$. After the resin was applied to plywood, the fancy veneer was overlaid on the plywood. The assemblies were subjected to 10-min open assembly time and 5-min closed assembly time at room temperature, and then pressed on $10 \mathrm{~kg} / \mathrm{cm}^{2}$ at $140^{\circ} \mathrm{C}$ for 300 seconds. The wood floorings were conditioned in the humidity chamber before testing. As shown in Fig. 3, the final dimension was 80 $\mathrm{mm}$ (Width) $\times 9.3 \mathrm{~mm}$ (Thickness) $\times 480$ $\mathrm{mm}$ (Length).

The $50 \mathrm{~mm} \times 50 \mathrm{~mm}$ specimens were cut from each sample board and tested as indicated in internal bonding testing procedure in $\mathrm{KS} \mathrm{F}$ 3200 (KSA, 2006) for determining the fracture toughness of glueline between fancy wood veneer and plywood with a Universal Testing Machine. The specimens were cut to the $20 \mathrm{~mm}$ along the glueline between plywood and fancy veneer as shown in Fig. 4, then the tensile load was applied to the samples at a rate of 1 $\mathrm{mm} / \mathrm{min}$ and the breaking load was measured to 


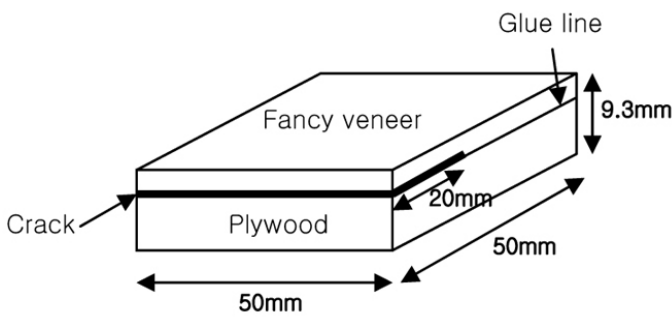

(a)

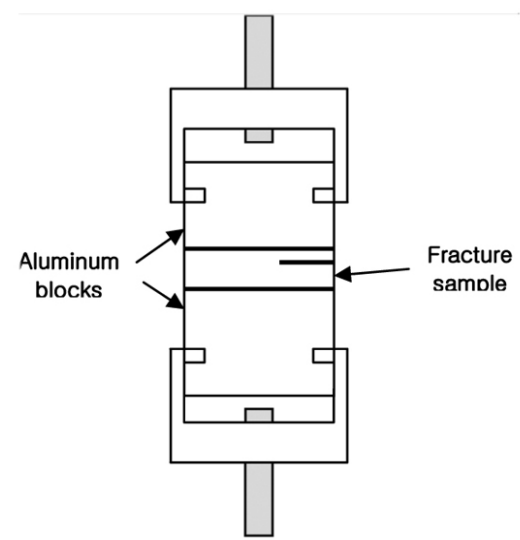

(b)

Fig. 4. Mode I fracture test specimens of plywood flooring (a) and testing configuration (b).

get the stress intensity factor $\left(\mathrm{K}_{\mathrm{IC}}\right)$ of wood flooring.

For the determination of formaldehyde emission, 12 specimens $(150 \mathrm{~mm} \times 50 \mathrm{~mm})$ per each condition were prepared, and the formaldehyde emission of the specimens were measured by the 24-hour desiccator method according to KS M 1998-4 (KSA, 2005).

\section{FRACTURE MECHANICS on FAILURE in ADHESIVE JOINTS}

Failure will also very much depend on the opening mode of the joint. Mode I is an opening or tensile mode where the loadings are normal to the crack. Mode II is a sliding or

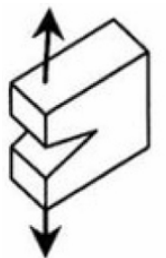

(a)

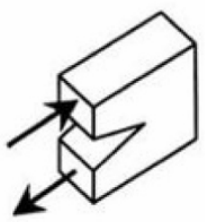

(b)

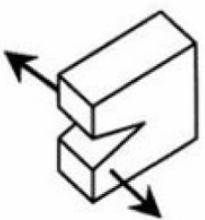

(c)
Fig. 5. Fracture mode of failure (a; opening mode; b; sliding or inplane shear mode; $\mathrm{c}$; tearing or antiplane sliding mode).

in-plane shear mode where the crack surfaces slide over one another in direction perpendicular to the leading edge of the crack. Mode III is a tearing or anti-plane sliding mode (Fig. 5).

Among fracture mode of failure, the mode I is considered the most important mode in engineering failures (Conrad et al., 2003). Several researches was carried out to determine the fracture toughness of wood based materials in Mode I fracture failures (Lei and Wilson, 1979; $1980 ; 1981)$. Mode I fracture was introduced to evaluate the glue bond quality in wood flooring in this study. The stress condition around crack tip is described by the stress intensity factor (K). Fracture occurs when the stress intensity factor reaches a critical level and this level is called critical stress intensity factor $(\mathrm{Kc})$. Mode I fracture toughness is most easily measured of the three modes and the general equation of stress intensity factor in Mode I fracture for single edge cracked plate in tension is;

$$
\begin{aligned}
& K_{I C}=\sigma_{M a x} \sqrt{\pi l} f \\
& \text { Where } \sigma_{\text {Max }}=\text { maximum stress } \\
& \quad l=1 / 2 \text { of crack length } \\
& \quad f=\text { specimen geometry function }
\end{aligned}
$$

The adhesive and wood have different mechanical properties. When a bonded material is subjected to some force, as shown in Fig. 6, the 
Preliminary Study of Rapeseed Flour-based Wood Adhesives for Making Wood Flooring

Table 1. Average density and moisture content of plywood flooring overlayed with fancy veneer

\begin{tabular}{cccc}
\hline \multicolumn{2}{c}{ Density $\left(\mathrm{g} / \mathrm{cm}^{3}\right)$} & \multicolumn{2}{c}{ Moisture content $(\%)$} \\
\hline \hline Average & $\begin{array}{c}\text { Standard } \\
\text { deviation }\end{array}$ & Average & $\begin{array}{c}\text { Standard } \\
\text { deviation }\end{array}$ \\
\hline 0.58 & 0.045 & 4.8 & 0.241 \\
\hline
\end{tabular}

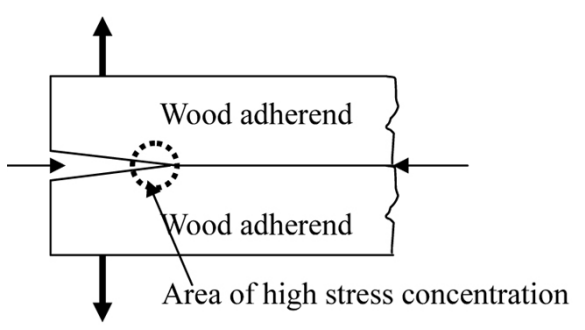

Fig. 6. Stress concentration around crack tip.

resultant stress is concentrated around the discontinuities far above the average stress in the joint (River, 1994). Fracture results when the stress at a discontinuity reaches the ultimate stress of either the adhesive, the adherend, or the interface.

The cracks in glue bond were made between fancy veneer and plywood using band saw to $20 \mathrm{~mm}$ length and equation (1) is transformed as follows;

$$
K_{I C}=\sigma_{M a x} l^{\frac{1}{2}} Y\left(\frac{l}{w}\right)
$$

Where $\sigma_{\text {Max }}=$ maximum stress

$l=1 / 2$ of crack length

$W=$ width of specimens

$$
\begin{aligned}
Y\left(\frac{l}{W}\right)= & 1.99-0.41\left(\frac{l}{W}\right)+18.70\left(\frac{l}{W}\right)^{2} \\
& -38.48\left(\frac{l}{W}\right)^{3}+53.85\left(\frac{l}{W}\right)^{4}
\end{aligned}
$$

Table 2. Formaldehyde emission of plywood flooring overlayed with fancy veneer by desiccator methods

\begin{tabular}{ccc}
\multirow{2}{*}{ Molar ratio } & \multicolumn{2}{c}{ Overlayed fancy veneer (unit: $\mathrm{mg} / \mathrm{L}$ ) } \\
\cline { 2 - 3 } & Boliva & Oak \\
\hline \hline 1.8 & $0.052(0.024)$ & $0.030(0.013)$ \\
2.1 & $0.081(0.042)$ & $0.030(0.011)$ \\
2.4 & $0.015(0.009)$ & $0.044(0.017)$ \\
\hline \multirow{3}{*}{ KSF 3111 } & $\mathrm{SE}_{0} ; 0.3 \mathrm{mg} / \mathrm{L}$ \\
& $\mathrm{E}_{0} ; 0.5 \mathrm{mg} / \mathrm{L}$ \\
& $\mathrm{E}_{1} ; 1.5 \mathrm{mg} / \mathrm{L}$ \\
\hline
\end{tabular}

The number in the parenthesis of each column means the standard deviation of formaldehyde emission values.

\section{RESULTS and DISCUSSION}

\subsection{Density and Moisture Contents of Wood Flooring}

The density and moisture contents of manufactured wood flooring samples are shown in Table 1.

The average density and moisture content of plywood flooring was 0.58 and $4.8 \%$ respectively, and the moisture content of plywood flooring met the requirement of $13 \%$ specified in KS F 3111 (KSA, 2008). The low moisture content was due to excessive evaporation of moisture during high temperature hot pressing.

\subsection{Formaldehyde Emission of Wood Flooring}

Table 2 shows the average values of formaldehyde emission of wood flooring bonded with rapeseed flour adhesive resins. The formaldehyde emissions of all specimens satisfied requirement of $\mathrm{SE}_{0}$ specified in the KS F 3200 $(0.3 \mathrm{mg} / \mathrm{L})$. As the molar ratio was increased, the formaldehyde emission was slightly increased, but the difference was not significant 


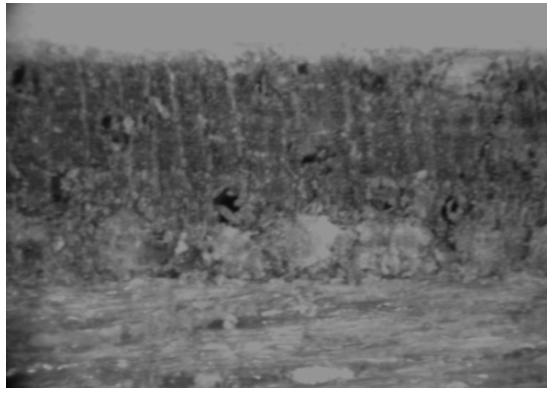

(a)

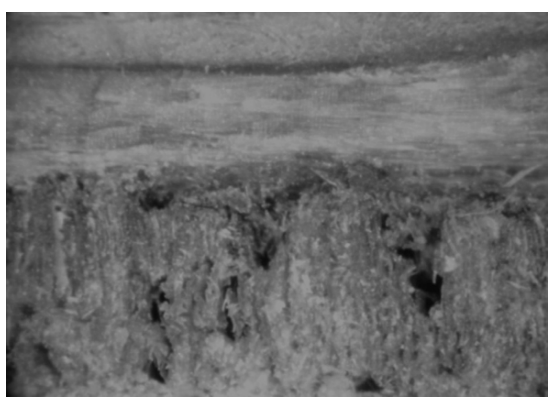

(b)

Fig. 7. Penetration of formulated adhesives (a: overlayed with boliva fancy veneer, b: overlayed with oak fancy veneer).

in wood flooring overlayed with oak fancy veneer. The wood flooring overlayed with boliva fancy veneer showed minimum emission in 2.4 molar ratio and this was considered good consolidation in formulated adhesives. From the results, the wood flooring manufactured bonded with rapeseed flour adhesive resin showed good characteristics in the formaldehyde emission and then this adhesive system is considered as environmentally friendly wood adhesives for binding flooring materials and gives proper opportunity in making environmentally friendly wood flooring system.

\subsection{Resin Penetration}

The adhesive glueline layer between fancy veneer and plywood was investigated to eval-

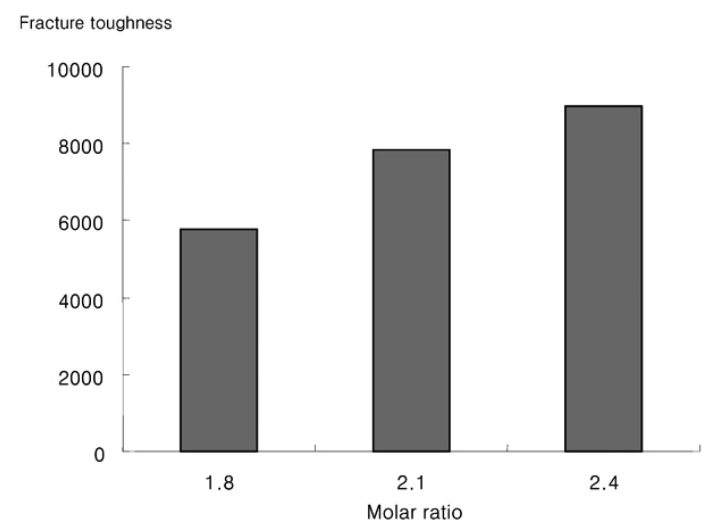

Fig. 8. Fracture toughness of plywood flooring overlayed with fancy veneer using formulated adhesives (unit: $N \sqrt{m m} / \mathrm{mm}^{2}$ ).

uate the penetration characteristics of adhesives into wood flooring materials using stereo microscope. The species of fancy veneer and plywood face layer are hardwood and hardwood is primarily composed of vessel elements, parenchyma cells and wood fiber. The main flow occurs primarily through vessel elements and the rapeseed flour adhesive penetrated sufficiently into the vessel elements and lumens in fancy veneer (Fig. 7). Especially the oak fancy veneer has large vessel elements and the adhesive resin penetrated easily into the vessel elements. Then they were crosslinked each other and mechanically connected to fancy veneer-adhesive resin-plywood and this gave strong bond quality to the wood flooring. From the results, the formulated adhesives were considered efficiently used to bond fancy veneer onto the plywood to make wood flooring system.

\subsection{Fracture Toughness $\left(K_{I C}\right)$ of Adhesive Bonded Wood Flooring}

The stress intensity factor of boliva overlayed wood flooring was increased with increasing molar ratio and this was considered as increased 
crosslinking tendency with increasing molar ratio (Fig. 8). The stress intensity factor of oak overlayed wood flooring showed same tendency with increasing molar ratio. From the results, the fracture mechanics was efficiently used to evaluate the gluebond quality using stress intensity factor.

\section{CONCLUSIONS}

The average density and moisture content of plywood flooring was $0.58 \%$ and $4.8 \%$ respectively, and the moisture content of plywood flooring met the requirement of $13 \%$ specified in KS standard. The adhesives mixed with rapeseed flour hydrolyzate and PF prepolymer was applied to the making wood flooring bonded with fancy veneer onto the plywood. The formaldehyde emissions of wood flooring met the requirement of the standard of $\mathrm{SE}_{0}$ specified in the KS standard. Higher molar ratio led to high formaldehyde emission, but the all specimens were lower than the minimum requirement about $\mathrm{SE}_{0}$ in $\mathrm{KS}$ standard. The rapeseed flour adhesive penetrated sufficiently into the vessel elements and lumens in fancy veneer and plywood. They were mechanically connected and this gave strong bond quality to the wood flooring. The critical stress intensity factor $\left(\mathrm{K}_{\mathrm{IC}}\right)$ of boliva overlayed wood flooring was increased with increasing molar ratio and this was the same tendency in oak overlayed wood flooring. From the results, the formulated adhesives were efficiently used to bond fancy veneer onto the plywood to make wood flooring.

\section{ACKNOWLEDGEMENTS}

This study was supported by the Technology Development Program for Agriculture and Forestry, Ministry of Agriculture and Forestry, Republic of Korea.

\section{REFERENCES}

1. Barbosa, A. P., E. B. Mano, and C. T. Andrade. 2000. Tannin-based resins modified to reduce wood adhesive brittleness. For. Prod. J. 50(9): 89 $\sim 92$.

2. Christiansen, A. W. and R. H. Gillespie. 1986. Potential of carbohydrates for exterior-type adhesives. For. Prod. J. 36(7/8): 20 28.

3. Conrad, M. P. C., G. D. Smith, and G. Fernlund. 2003. Fracture of discontinuous wood-adhesive bonds. International $\mathrm{J}$. of Adhesion and Adhesives 23: $39 \sim 47$.

4. Korean Standard Association. 2006. Fiberboards. KS F 3200.

5. Korean Standard Association. 2006. Determinatuion of the formaldehyde emission of building interior products. -Part 4. Desiccator method. KS M 1998-4.

6. Korean Standard Association. 2008. Natural wood veneer flooring board. KS F 3111.

7. Kuo, M. L., D. J. Myers, H. Heemstra, D. Curry, D. O. Adams, and D. D. Stokke. 2001. Soybeanbased adhesive resins and composite products utilizing such adhesives. U.S. Patent 6,306,997.

8. Lei, Y. and J. B. Wilson. 1979. Fracture toughness of parallel-laminated veneer. For. Prod. J. 29: $28 \sim 32$.

9. Lei, Y. and J. B. Wilson. 1980. Fracture toughness of oriented flakeboard. Wood Science 12: $154 \sim 161$.

10. Lei, Y. and J. B. Wilson. 1981. A model for predicting fracture toughness of flakeboard. Wood Science 13: $151 \sim 156$.

11. Oh, Y., T. Seller Jr. T, M. G. Kim, and R. C. Strickland. 1994. Evaluation of phenol-formaldehyde OSB resins modified with lignin residues from acid-hydrolyzed waste newsprint. For. Prod. J. 44(2): $25 \sim 29$.

12. Olivares, M., H. Aceituno, G. Neiman, E. Rivera, and T. Seller Jr. 1995. Lignin-modified phenolic adhesives for bonding Radiata pine plywood. For. Prod. J. 45(1): $63 \sim 67$.

13. Riebel, M. J., P. L. Torgusen, K. D. Roos, D. E. Anderson, and C. Gruber. 1997. Bio-composite material and method of making. U.S. Patent $5,635,123$. 
In Yang, Syehee Ahn, In-gyu Choi, Gyu-seong Han, and Seichang Oh

14. River, B. H. 1994. Fracture of adhesive-bonded wood joints, In: Handbook of Adhesive Technology. pp. 151 177. Marcel Dekker.

15. Steele, P. H., R. E. Kreibich, P. J. Steynberg, and
R. W. Hemingway. 1998. Finger jointing green southern yellow pine with a soy-based adhesive. Adhesive Age (October): 49 54. 